\title{
Settling Saskatchewan
}

\author{
by B. Alan Anderson \\ Regina: University of Regina Press 2013 \\ ISBN: 978-0-88977-284-7 \\ Softcover, $\$ 25.04,485$ pp. \\ Reviewed by Harry H. Hiller
Department of Sociology, University of Calgary
}

Saskatchewan is often thought of in terms of how staples (particularly wheat) have contributed to the national economy. What is less widely acknowledged is the role the province has played as a destination and launching point for people making Canada their home. One of the primary goals of the National Policy of 1879 was to populate the West as an economic hinterland supporting central Canadian industry. In 1896, the immigration policies of the Minister of the Interior, Clifford Sifton, played a huge role in attracting a massive influx of people of European background to the weakly populated West—and particularly Saskatchewan. The migration of people to Saskatchewan was so significant in such a short time that by 1931, Saskatchewan was the third most populated province in Canada. The Homestead Act had made a quarter-section of land available for $\$ 10$ for new settlers, and during Sifton's administration alone, over 115,000 homestead claims were filed. In some ways, and for a variety of reasons, the province quickly became overpopulated, so that out-migration became a recurrent issue in succeeding years. What is intriguing, then, is the role which Saskatchewan has played in the Canadian demographic drama.

Anderson has produced a remarkable and stimulating book chronicling the settlement process in Saskatchewan. Having spent his entire career in the province, visited all corners of the province and its many communities, and personally observed changes over time, Anderson is in an excellent position to describe the outcomes of settlement in rich detail. He provides considerable historical and statistical material on what seems to be almost every community in Saskatchewan, noting who settled there and how the ethnic composition of the community has changed. The driving theme of the book is that the settlement of the province was essentially rural, and that it occurred through ethnic blocs or ethno-religious blocs. While the notion of bloc settlement suggests considerable homogeneity within that bloc, Anderson takes a broader view and understands blocs as also including lower concentrations of similar ethnic groups. Perhaps a better term for the many cases of lower ethnic concentrations might simply be ethnic clustering, but the point is nevertheless clear that co-ethnics tended to settle together, whether in a planned colony or in a more dispersed way among other ethnic groups. Anderson goes up and down the province in great detail, beginning with the largest ethnic groups and moving to the smallest groups, to demonstrate the diversity of settlement within the province. Each chapter deals with a different ethnic origin, including British, Germanic, Ukrainian and Polish, Other Eastern European Groups, and French and Nordic settlements. Chapter 9 deals with more recently arrived urban minorities, and seems a bit out of place, given the primary focus on the early settlement period in rural areas and the outcomes for these communities.

While much of the detail in these discussions becomes a blur-particularly, as someone less familiar with Saskatchewan's communities, I had no idea where many of these towns and villages are even located (there is no map in the book), and it was difficult to keep up with the changes in numbers of inhabitants in these locations from year to year (there are no charts, tables, or figures in the book to help conceptualize these changes) - I found this discussion stimulating for a variety of reasons. First, it became clear that while Europeans were the 
people who settled in Saskatchewan, many did not come directly from Europe but came via the United States or another Canadian province. For example, the town of Esterhazy was settled by Hungarian coal miners and steel industry workers from Pennsylvania, and the town was named after Count Esterhazy, who helped settle the area but who had adopted an aristocratic name with which he had not been born. There is a hidden story here of much step-wise migration in the province that could be explored further but which nevertheless is clearly documented. Second, in spite of the imagery of homogeneity that bloc settlement implies, Anderson provides interesting evidence of how divisions and conflicts existed within these groups. For example, he shows how Ukrainians were split into factions such as Orthodox vs. Catholic, assimilationists vs. traditionalists, and multiculturalists vs. independence nationalists, and notes how illiteracy and failure to learn the language contributed to mistreatment and slower assimilation. He also shows how Finnish settlers were divided between "Church Finns" and "Red Finns." Another interesting discussion pertains to how the Doukhobor notion of communal settlement was in conflict with the Homestead Act, which required individual settlement on the land. Third, the book provides very strong evidence of the relationship between religion and ethnicity in the settlement process. Markers of this relationship were the religious organizations and buildings within each community, always discussed as pivotal identifiers for all groups as co-ethno-religionists. Fourth, it was interesting to learn fascinating details about groups in Saskatchewan, such as the French community known as the Fransaskois, who identify with the French language and culture but do not necessarily speak it. Or the Oklahoma Blacks, who initially settled in the Eldon District — they produced a football player who became a star in the NFL. Anderson also discusses the Wapella settlement of Russian Orthodox Jews, which produced the Bronfman family, later of Seagrams Distillery fame in Montreal. So, amidst the myriad discussions of places and communities I did not know were these intriguing details that brought the social context of Saskatchewan to life in an interesting way. It also provoked me to think about all the people in my family and friendship circle who at one time had had heritage links to Saskatchewan that were not obvious given their current residential histories.

Anyone interested in the history and context of Saskatchewan will find this book helpful. Anderson's bibliography at the end of each chapter provides many useful references for the groups he has studied. In many ways, the book will be the legacy of the life's work of Alan Anderson, who has been interested in the ethnic communities of the province at least since his doctoral work, which he utilizes often in the book, going back to 1968-72. It might have been good if he had been able to update some of the studies he had done at that time for his analysis in this book. He also promised a theoretical framework in the last chapter for the mountains of material contained in the book, but the theory is rather weak. He uses an interesting interpretive concept (delocalization) proposed by Greer in 1964 to explain why the character of these bloc settlements are changing, but it would have been good to use some of the more recent literature in order to help him develop a theoretical/interpretive framework that would have made even a broader contribution. Anderson's book raises many intriguing questions that can now be answered by the next generation of scholars. He has provided baseline data and observations that will now prompt others to explore issues more deeply, such as: What is the future of rural ethnicity in the face of rural depopulation and corporate farming? How will out-migration from the province and the in-migration of persons with different characteristics (and mostly to urban centers) change the way the province has always understood itself ethnically? This book is significant because it draws our attention to the role played by bloc settlements in the original settlement of the province. Whether this process is totally unique to Saskatchewan is another question, but its role for the province is indisputable. The next question is to determine whether these historic ethnic identities/associations will only continue to exist in a symbolic sense in the future. So far, Anderson implies that tradition and change can coexist, but it is an issue that will require further monitoring. 